\title{
Bovine $\alpha$-Lactalbumin Stimulates Mucus Metabolism in Gastric Mucosa
}

\author{
Y. Ushida, ${ }^{* 1}$ Y. Shimokawa, ${ }^{\star}$ T. Toida, ${ }^{*}$ H. Matsui, $†$ and M. Takase ${ }^{\star}$ \\ *Biochemical Research Laboratory, Morinaga Milk Industry Co. Ltd., Zama, Kanagawa 228-8583, Japan \\ †Institute of Clinical Medicine, University of Tsukuba, Tsukuba, Ibaraki 305-8575, Japan
}

\begin{abstract}
Bovine $\alpha$-lactalbumin ( $\alpha$-LA), a major milk protein, exerts strong gastroprotective activity against rat experimental gastric ulcers induced by ethanol or stress. To elucidate the mechanisms underlying this activity, the influence of $\alpha$-LA on gastric mucus metabolism was investigated in vitro and in vivo. For the in vitro study, RGM1 cells (a rat gastric epithelial cell line) were selected for observation of the direct activity of $\alpha$-LA on gastric mucosal cells and cultured in the presence of either $\alpha$-LA or ovalbumin (OVA), a reference protein showing no gastroprotective activity. Amounts of synthesized and secreted mucin, a major component of mucus, were determined using $\left[{ }^{3} \mathrm{H}\right]$ glucosamine as a tracer, and prostaglandin $\mathrm{E}_{2}\left(\mathrm{PGE}_{2}\right)$ levels in the culture medium were determined by RIA. For the in vivo study, the thickness of the mucus gel layer, a protective barrier for gastric mucosa, was evaluated histochemically in rat gastric mucosa. $\alpha$-Lactalbumin $(3 \mathrm{mg} / \mathrm{mL})$ significantly stimulated mucin synthesis and secretion in RGM1 cells and also increased $\mathrm{PGE}_{2}$ levels in the culture medium. In contrast, OVA showed no enhancing effects under identical conditions. Neither indomethacin, a cyclo-oxygenase inhibitor, nor AH23848, a prostaglandin EP4 receptor antagonist, affected $\alpha$-LA-induced enhancement of mucin synthesis and secretion. In vivo, oral administration of $\alpha-\mathrm{LA}(300 \mathrm{mg} / \mathrm{kg} \times 3$ times/d $\times 7 \mathrm{~d}$ ) increased the thickness of the mucus gel layer in rats. These results indicate that $\alpha$-LA fortifies the mucus gel layer by stimulating mucin production and secretion in gastric mucus-producing cells, and that this enhancing effect is independent of endogenous $\mathrm{PGE}_{2}$. Comparison of the efficacy of $\alpha$-LA with OVA suggests that the activities observed in RGM1 cells are closely related to the gastroprotective effects in rat gastric ulcer models. In conclusion, $\alpha$-LA stimulates mucus metabolism, and this action may be responsible for its gastroprotective activity.
\end{abstract}

Key words: $\alpha$-lactalbumin, mucus, prostaglandin, gastroprotective activity

Received July 2, 2006.

Accepted September 26, 2006.

${ }^{1}$ Corresponding author: y_usida@morinagamilk.co.jp

\section{INTRODUCTION}

The biological properties of milk proteins have recently become the focus of study, in addition to their nutritional value. Some whey proteins have been reported to possess biological functions, including immunomodulatory, antitumorigenic, antibacterial, opioid, and antihypertensive activities (Gill and Cross, 2000; Shah, 2000). We have been interested in the actions of whey proteins on gastrointestinal mucosa, because these proteins first come into contact with the mucosa of the digestive tract after ingestion.

In previous studies, we have examined bovine whey proteins for gastroprotective activity in experimental gastric ulcer models (Matsumoto et al., 2001). The orally administered whey protein fraction exhibited preventive effects against ethanol-induced ulcers in rats, and $\alpha$-LA played a central role in this activity. Ethanol-induced gastric ulcer formation was strongly inhibited by $\alpha$-LA administration at an efficacy comparable to that of a commercially available antiulcer medicine. Stress-induced gastric ulcers were also prevented by $\alpha$-LA administration in rats.

The inherent defense mechanisms of gastric mucosa are very important for protection against ulcer formation by aggressive factors such as acid, pepsin, alcohol, drugs, and stress (Silen, 1987). The fact that pretreatment with $\alpha$-LA was effective in preventing experimental ulcers led us to investigate the effects of $\alpha$-LA on gastric defense in naive rats. The results demonstrated that $\alpha$-LA enhanced several defense mechanisms, and predicted that the enhanced defense mechanisms induce strengthening and protection of the gastric mucosa against aggressive factors (Ushida et al., 2003).

Gastric mucus, one of the principal factors in gastric defense mechanisms, is localized in 3 phases in vivo: in the gastric fluid, in the mucus gel layer adhering to the mucosal surfaces, and in the granules of mucusproducing cells (Daugherty et al., 1991; Allen and Flemström, 2005). Mucin, a major component of mucus, is a high-molecular-weight substance comprising $>80 \%$ sugar. Mucin maintains the gel-forming and viscoelastic features of gastric mucus. This macromolecule is synthesized in gastric mucus-producing cells, secreted into the gastric lumen, and forms the mucus gel layer 
on the gastric mucosal surface. The mucus gel layer is an important defensive barrier, covering gastric epithelial cells and holding bicarbonate ions to neutralize hydrogen ions that diffuse back into the gastric mucosa. However, this layer is frequently disrupted by acid, pepsin, bile salts, alcohol, and other injurious agents in the gastric lumen, resulting in damage to gastric epithelial cells. Maintaining mucus metabolism, including preservation of the mucus gel layer and continuous synthesis and secretion of mucin, is thus important to ensure protection of the gastric mucosa.

Although we previously demonstrated that $\alpha$-LA increases the mucin content of both the gastric fluid and the mucus gel layer in rat gastric mucosa (Ushida et al., 2003), the details of this action have remained unclear. We considered that up-regulation of mucus metabolism by $\alpha$-LA may contribute to the gastroprotective actions. The present study investigated the influence of $\alpha$-LA on mucus metabolism in vitro and in vivo. First, using a rat gastric epithelial cell line (RGM1) originating from normal gastric mucosa (Kobayashi et al., 1996), we examined whether $\alpha$-LA affects mucin synthesis and secretion at the cellular level. Ovalbumin (OVA), which is completely ineffective in preventing ethanol- or stress-induced gastric ulcers (Y. Ushida, unpublished data), was used as a reference protein to connect the activity of increased mucus metabolism in vitro with gastroprotective activity in the experimental ulcer models. We subsequently explored the potential involvement of endogenous prostaglandin $\mathrm{E}_{2}\left(\mathbf{P} \mathbf{G E}_{2}\right)$ in the actions of $\alpha$-LA on mucus metabolism in RGM1 cells, because $\mathrm{PGE}_{2}$ is known to play an important role in mucus metabolism (Miller, 1983; Wilson, 1991). Finally, we evaluated the mucus gel layer thickness histochemically to determine whether orally administered $\alpha$-LA was effective in strengthening the mucosal barrier in rat gastric mucosa. We demonstrate herein that $\alpha$ LA enhances mucus metabolism and that this action probably contributes to the protective actions of this protein.

\section{MATERIALS AND METHODS}

\section{In Vitro Study}

Materials. $\alpha$-Lactalbumin, OVA, and AH23848 (a prostaglandin EP4 receptor antagonist) were purchased from Sigma Chemical (St. Louis, MO). Indomethacin (a cyclo-oxygenase inhibitor) was obtained from Wako Pure Chemical Industries (Osaka, Japan), and $\left[{ }^{3} \mathrm{H}\right]$ glucosamine was from MP Biomedicals (Irvine, CA). Indomethacin and AH23848 were dissolved in dimethyl sulfoxide. The final concentration of dimethyl sulfoxide was $0.3 \%$ in culture media. This concentration of dimethyl sulfoxide was confirmed to exert no inhibi- tory effects on mucin synthesis or secretion in RGM1 cells.

Cell Culture. RGM1 cells were obtained from Riken Bioresource Center (Ibaraki, Japan). Cells were maintained in a 1:1 mixture of Dulbecco's modified Eagle's medium and Ham's F-12 medium (DMEM/F12) supplemented with $20 \%$ fetal bovine serum (FBS) at $37^{\circ} \mathrm{C}$ under $5 \% \mathrm{CO}_{2}$ in air. Cells that reached confluence in a 12-well culture plate were used for the experiments.

Measurement of Mucin Synthesis in RGM1 Cells. The amount of synthesized mucin was determined according to the methods of Terano et al. (1986). RGM1 cells were cultured in DMEM/F12 supplemented with $10 \%$ FBS containing $\left[{ }^{3} \mathrm{H}\right]$ glucosamine $(10 \mu \mathrm{Ci} / \mathrm{mL})$ and test compounds. To investigate the participation of endogenous $\mathrm{PGE}_{2}$ in the actions of $\alpha$-LA on mucin synthesis, cells were preincubated with indomethacin at 10 $\mu M$ for $4 \mathrm{~h}$ or AH23848 at $100 \mu M$ for $2 \mathrm{~h}$ before adding $\alpha$-LA. Indomethacin and AH23848 remained in the culture medium until the end of the experiment. After $48 \mathrm{~h}$, the culture medium was recovered. Cells were solubilized with $50 \mathrm{~m} M$ Tris-HCl buffer ( $\mathrm{pH}$ 7.2) containing $2 \%$ Triton $\mathrm{X}-100$, and cell lysate was incubated at $37^{\circ} \mathrm{C}$ for $1 \mathrm{~h}$ to extract the mucin, as described by Azuumi et al. (1980). An aliquot of medium or cell lysate extract was mixed with absolute ethanol to make a $75 \%$ ethanol solution ( $\mathrm{vol} / \mathrm{vol})$. The mixture was kept on ice for $10 \mathrm{~min}$ and centrifuged at $12,000 \times \mathrm{g}$ for $10 \mathrm{~min}$ at $4^{\circ} \mathrm{C}$. The resulting pellet was washed 3 times with $75 \%$ ethanol and solubilized in $0.5 \mathrm{M} \mathrm{NaOH}$. Sample radioactivity was measured using a liquid scintillation counter (LSC-6100; Aloka, Tokyo, Japan). The amount of synthesized mucin was expressed as the sum of mucin contents from the medium and cell lysate.

Measurement of Mucin Secretion in RGM1 Cells. RGM1 cells were cultured for $24 \mathrm{~h}$ in DMEM/F12 supplemented with $20 \%$ FBS containing $\left[{ }^{3} \mathrm{H}\right]$ glucosamine $(10 \mu \mathrm{Ci} / \mathrm{mL})$. Cells were washed 3 times with DMEM/ F12 and then incubated in DMEM/F12 with $10 \%$ FBS in the presence of test compounds. For the inhibitory study with $\mathrm{PGE}_{2}$, cells were preincubated with indomethacin at $10 \mu M$ or AH23848 at $100 \mu M$ for $30 \mathrm{~min}$ before treatment with $\alpha$-LA. Both drugs remained in the culture medium until the end of the experiment. After $9 \mathrm{~h}$, the culture medium was collected. The mucin content of the medium was determined by ethanol precipitation, as described above.

Measurement of PGE $E_{2}$ in RGM1 Cells. Cell culture was incubated in DMEM/F12 with $10 \%$ FBS containing the test compounds. After $9 \mathrm{~h}$, the culture medium was recovered. Prostaglandin $\mathrm{E}_{2}$ was extracted from the culture medium using an octadecylsilane-bound silica solid-phase extraction method with a Sep-Pak $\mathrm{C}_{18}$ cartridge (Waters, Milford, MA; Powell, 1982) and was 
measured using a RIA kit (GE Healthcare BioSciences, Piscataway, NJ).

\section{In Vivo Study}

Animals. Male Wistar rats were purchased from Japan SLC (Shizuoka, Japan) at 9 wk of age and were housed in plastic cages with wire-net floors to prevent coprophagy, in an air-conditioned room with a 12 -h light/dark cycle. Animals were allowed ad libitum access to a normal laboratory diet and tap water. All animals were handled in accordance with Law No. 105 and Notification No. 6 of the Japanese Government.

Treatment. Rats were randomly assigned to 2 groups after a 1-wk acclimation period and were then intragastrically administered either $\alpha$-LA (Davisco Foods International, Eden Prairie, MN) at $300 \mathrm{mg} / \mathrm{kg}$ of BW in a volume of $5 \mathrm{~mL} / \mathrm{kg}$, or the vehicle (distilled water), 3 times/d for 7 consecutive days.

Histochemical Examination. At $1 \mathrm{~h}$ after final administration of $\alpha$-LA or the vehicle, each rat was killed under ether anesthesia and the stomach was excised. The stomach was cut along the greater curvature, fixed in Carnoy's fixation liquid for $1 \mathrm{~h}$, and routinely processed for paraffin embedding. Sections were stained using periodic acid-Schiff (PAS) reagent, and the thickness of the mucus gel layer was measured under light microscopy by an observer who was blinded to the treatment administered. The ratio of mucus gel layer thickness to that of the lamina propria mucosae was calculated as a percentage.

\section{Statistical Analysis}

Statistical analysis of differences between the control and treated groups was performed using Dunnett's $t$ test. Values of $P<0.05$ were considered statistically significant, and all analyses were performed using JMP version 4.0 software (SAS Institute, Cary, NC).

\section{RESULTS}

\section{In Vitro Study}

Effects of $\alpha-L A$ and OVA on Mucin Synthesis in RGM1 Cells. $\alpha$-Lactalbumin (1 and $3 \mathrm{mg} / \mathrm{mL}$ ) enhanced the synthesis of mucin in a dose-dependent manner (107 and 123\% of the control, respectively; Figure 1). Significant enhancement was identified for the dose of $3 \mathrm{mg} / \mathrm{mL}(P<0.05)$. Conversely, OVA ( 1 and 3 $\mathrm{mg} / \mathrm{mL}$ ) did not affect mucin synthesis.

Effects of $\alpha-L A$ and OVA on Mucin Secretion in RGM1 Cells. Figure 2 shows the secretion of mucin from RGM1 cells into the culture medium. $\alpha$-Lactalbumin increased the mucin content of the culture medium

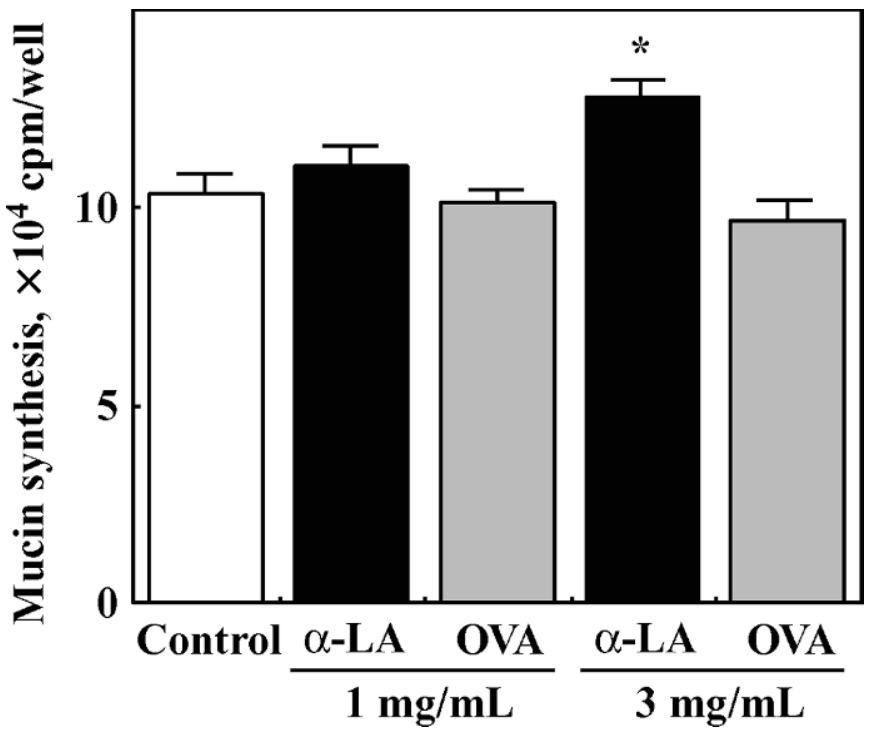

Figure 1. Effects of $\alpha$-LA and ovalbumin (OVA) on mucin synthesis in RGM1 cells. Values represent mean \pm SEM for 5 cultures. $* P<$ 0.05 , compared with the control.

in a dose-dependent manner. The rate of increase at 3 $\mathrm{mg} / \mathrm{mL} \alpha$-LA was $119 \%$ of the control value $(P<0.01)$. Ovalbumin did not increase the mucin content of the medium.

Effects of $\alpha-L A$ and OVA on PGE 2 Synthesis in RGM1 Cells. Figure 3 shows the results of $\mathrm{PGE}_{2}$ synthesis in RGM1 cells. $\alpha$-Lactalbumin increased the amount of $\mathrm{PGE}_{2}$ in culture medium (140\% of the control;

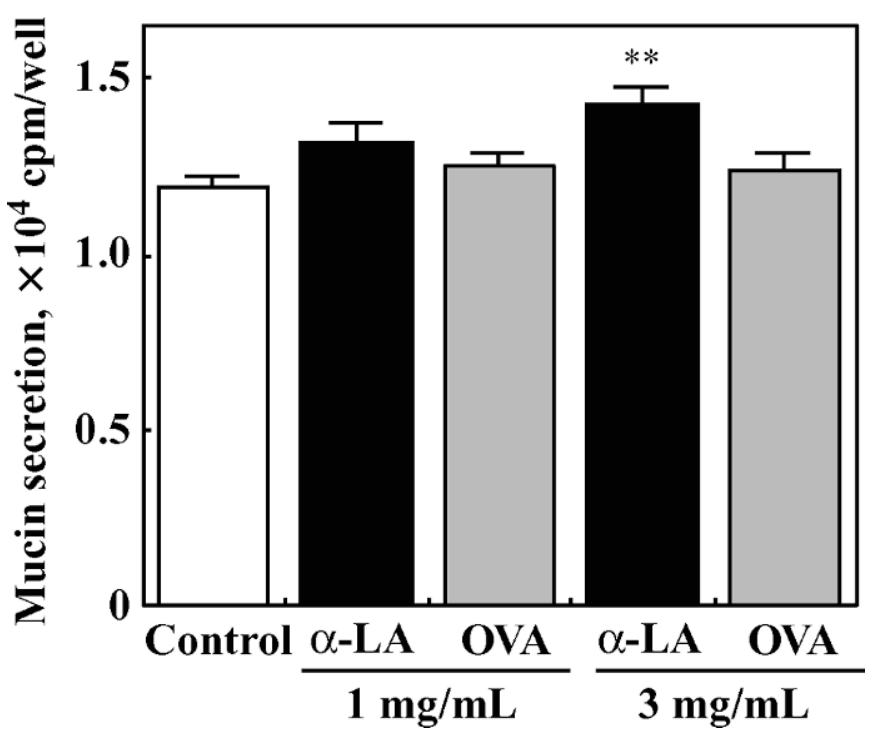

Figure 2. Effects of $\alpha$-LA and ovalbumin (OVA) on mucin secretion in RGM1 cells. Values represent mean \pm SEM for 5 cultures. $* * P<$ 0.01, compared with the control. 


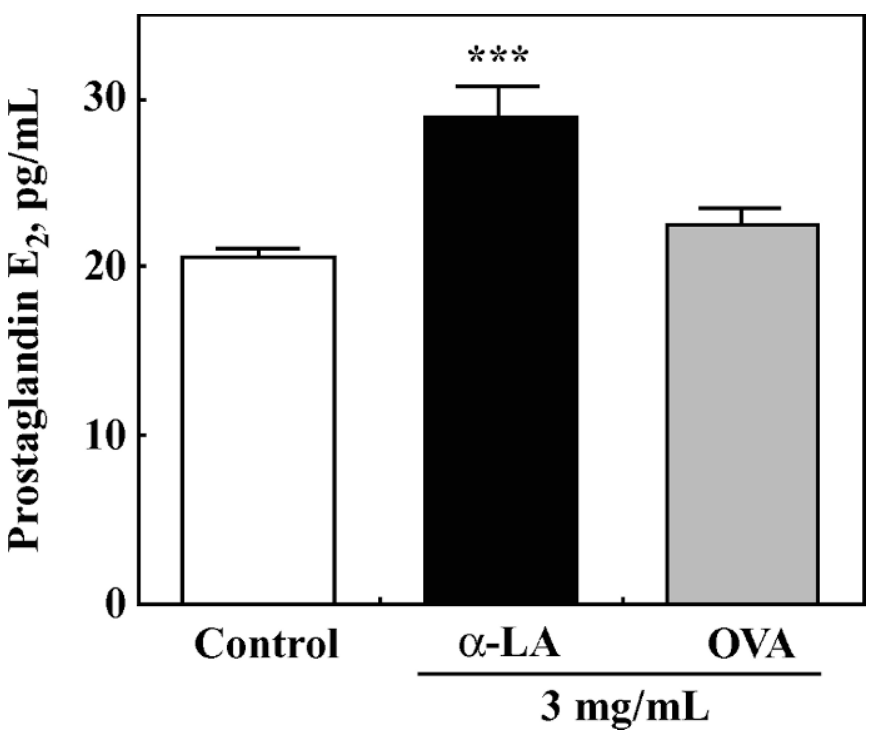

Figure 3. Effects of $\alpha$-LA and ovalbumin (OVA) on prostaglandin $\mathrm{E}_{2}$ synthesis in RGM1 cells. Values represent mean \pm SEM for 5 cultures. ${ }^{* * *} P<0.001$, compared with the control.

$P<0.001)$. Ovalbumin did not affect $\mathrm{PGE}_{2}$ synthesis in RGM1 cells.

Effects of Indomethacin and AH23848 on $\alpha-L A$ Induced Enhancement of Mucin Synthesis and Secretion in RGM1 Cells. To investigate the involvement of endogenous $\mathrm{PGE}_{2}$ in $\alpha$-LA-induced mucin metabolism, cells were preincubated with 2 inhibitors of the $\mathrm{PGE}_{2}$ pathway. As shown in Table 1, indomethacin and AH23848 had no effect on the increased mucin synthesis and secretion induced by $\alpha$-LA.

\section{In Vivo Study}

Effects of $\alpha$-LA on PAS-Positive Mucus in Rat Gastric Mucosa. Figure 4A shows representative photomicrographs of PAS-stained corpus and antrum mucosa from control and $\alpha$-LA-treated rats. The histologi-

Table 1. Effects of indomethacin and AH23848 on $\alpha$-LA-enhanced mucin synthesis and secretion ${ }^{1}$

\begin{tabular}{lll}
\hline Treatment & Mucin synthesis, ${ }^{2} \%$ & Mucin secretion, ${ }^{2} \%$ \\
\hline Control & $100.0 \pm 1.2$ & $100.0 \pm 1.8$ \\
Indomethacin & $106.7 \pm 1.3$ & $100.7 \pm 2.1$ \\
AH23848 & $112.9 \pm 2.1^{*}$ & $106.2 \pm 1.1$ \\
$\alpha$-LA & $133.4 \pm 3.5^{* * *}$ & $118.9 \pm 1.8^{* * *}$ \\
$\alpha$-LA + indomethacin & $132.4 \pm 5.1^{* * *}$ & $116.4 \pm 3.1^{* * *}$ \\
$\alpha$-LA + AH23848 & $153.7 \pm 2.3^{* * *}$ & $118.9 \pm 2.4^{* * *}$ \\
\hline
\end{tabular}

${ }^{1}$ Data are expressed as a percentage of the control value.

${ }^{2}$ Values represent mean \pm SEM for 5 to 11 cultures.

$* P<0.05$, compared with the control; $* * * P<0.001$, compared with the control.
A

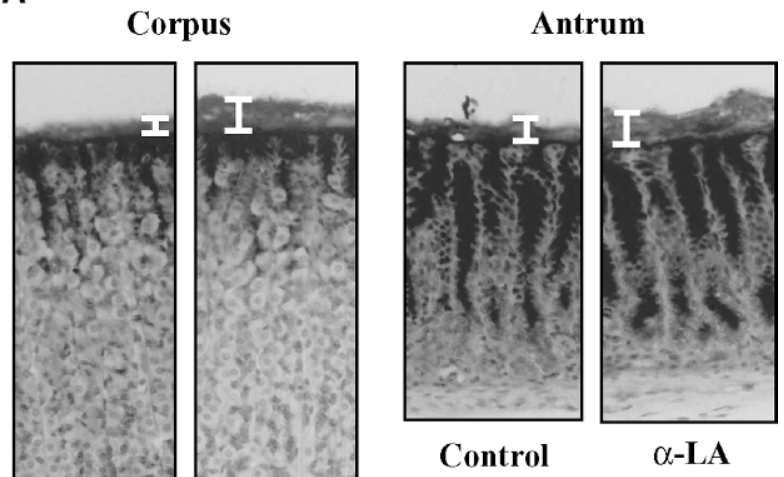

I:Mucus gel layer

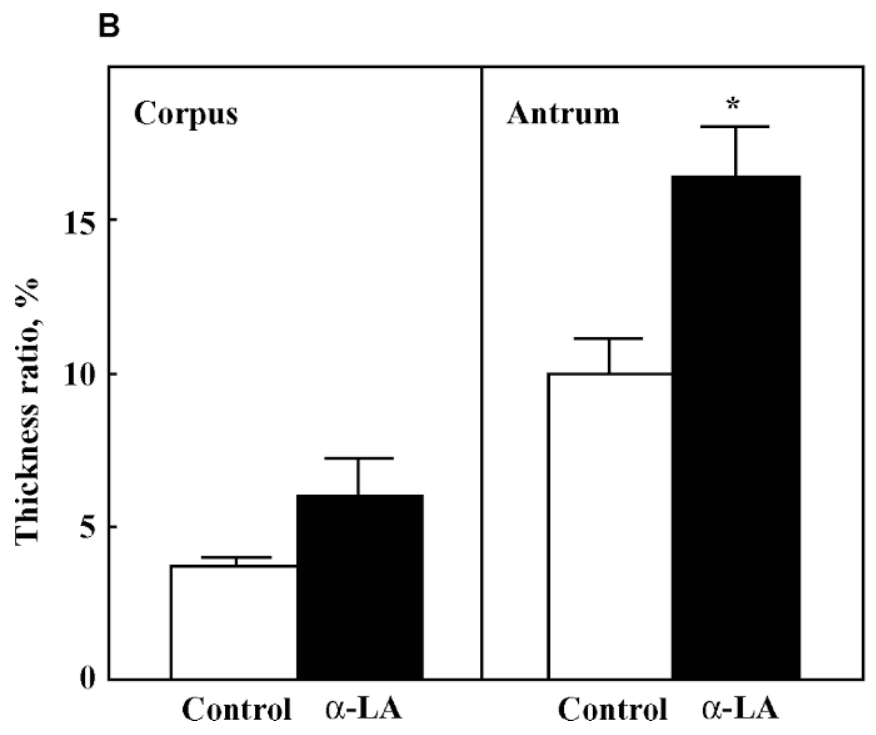

Figure 4. Effects of $\alpha$-LA on periodic acid-Schiff (PAS)-positive mucus in the gastric mucosa in rats. (A) Representative photomicrographs of corpus and antrum mucosa from control and $\alpha$-LA-treated rats. Sections were stained using PAS reagent. Original magnification: 33×. (B) Thickness ratio of the mucus gel layer to the lamina propria mucosae in corpus and antrum mucosa. Values represent mean \pm SEM for 6 rats. ${ }^{*} P<0.05$, compared with the control.

cal observation revealed that $\alpha$-LA did not affect the volume of PAS-positive intramucosal mucus in either corpus or antrum mucosa. Conversely, $\alpha$-LA increased the thickness of the mucus gel layer in both corpus 
( $163 \%$ of the control value) and antrum mucosa ( $164 \%$ of the control value, $P<0.05$; Figure $4 \mathrm{~B}$ ).

\section{DISCUSSION}

Forming a major whey protein in most milks, $\alpha$-LA is a calcium-binding protein with a molecular mass of $14 \mathrm{kDa}$ (Permyakov and Berliner, 2000). The essential function of $\alpha$-LA is to regulate the biosynthesis of lactose in the mammary gland. Several biological functions have recently been identified for $\alpha$-LA, such as apoptotic activity (Håkansson et al., 1995) and bactericidal activity (Pellegrini et al., 1999; Håkansson et al., 2000). In addition, we have previously reported gastroprotective activity involving the enhancement of gastric defense mechanisms (Matsumoto et al., 2001; Ushida et al., 2003). The present study focused on mucus metabolism to elucidate the mechanisms underlying the gastroprotective actions of $\alpha$-LA.

We first investigated the effects of $\alpha$-LA on mucin synthesis and secretion in RGM1 cells. This cell line, established from normal Wistar rat gastric mucosa, is a diploid and nontransformed epithelial cell line displaying the characteristics of gastric mucus-producing cells (Kobayashi et al., 1996). RGM1 cells are therefore considered a good model for studying the direct actions of $\alpha$-LA on the function of the gastric mucosal epithelium, including gastric mucus metabolism. Figures 1 and 2 show that $\alpha$-LA acted on gastric mucus-producing cells, inducing stimulation of both mucin production and secretion. We also investigated whether the actions of $\alpha$-LA were accompanied by $\mathrm{PGE}_{2}$ production in RGM1 cells. The results clearly showed that $\alpha$-LA increased the amount of $\mathrm{PGE}_{2}$ in the culture medium, meaning that $\alpha$-LA stimulated $\mathrm{PGE}_{2}$ synthesis in RGM1 cells (Figure 3). Moreover, we compared the above activity of $\alpha$-LA to that of OVA. This protein had previously failed to prevent experimental gastric ulcer formation in rats (Y. Ushida, unpublished data), and was used as a reference protein. Ovalbumin did not exert any effects on mucin synthesis, mucin secretion, or $\mathrm{PGE}_{2}$ production (Figures 1 to 3 ), suggesting that the $\alpha$-LA activity observed in RGM1 cells was closely related to the gastroprotective effects seen in rat gastric ulcer models.

Prostaglandins, particularly $\mathrm{PGE}_{2}$, are known to have strong antiulcer effects and to play key roles in gastric defense mechanisms, such as mucus, bicarbonate, microcirculation, and cell turnover (Miller, 1983; Wilson, 1991). Stimulation of mucus secretion by prostaglandins is one of the major mechanisms underlying their protective actions. Recent studies have revealed that receptors activated by E-type prostaglandins are divided into 4 subtypes: EP1, EP2, EP3, and EP4 (Cole- man et al., 1994a). The EP4 receptor has also been reported to be abundantly present on gastric mucusproducing cells, and $\mathrm{PGE}_{2}$ appears to stimulate mucus secretion via this receptor (Ding et al., 1997; Narumiya et al., 1999). In addition, Hassan et al. (1996) demonstrated that RGM1 cells express EP4 receptor mRNA and that mucin synthesis in RGM1 cells is stimulated by exogenous $\mathrm{PGE}_{2}$. These findings and the fact that $\alpha$-LA increased $\mathrm{PGE}_{2}$ production, as mentioned above, allowed us to confirm that endogenous $\mathrm{PGE}_{2}$ is involved in $\alpha$-LA-induced mucin metabolism when 2 inhibitors of the $\mathrm{PGE}_{2}$ pathway were used. However, neither indomethacin, as a cyclo-oxygenase inhibitor (Mitchell et al., 1994), nor AH23848, as a prostaglandin EP4 receptor antagonist (Coleman et al., 1994b), affected $\alpha$-LAinduced enhancement of mucin synthesis or secretion (Table 1). These results suggest that the stimulatory effects of $\alpha$-LA act independently of endogenous $\mathrm{PGE}_{2}$. In this context, several gastroprotective agents, such as epidermal growth factor and geranylgeranylacetone, have been reported to increase mucin synthesis and secretion in cultured cells through prostaglandin-independent pathways (Terano et al., 1986; Shimamoto et al., 2003). To date, the prostaglandin-independent pathways for mucin metabolism remain unclear. Further investigation of such pathways might elucidate the precise mechanisms underlying $\alpha$-LA-induced stimulation of mucus metabolism.

Our previous studies demonstrated that orally administered $\alpha$-LA increases the amount of $\mathrm{PGE}_{2}$ in gastric tissue in rats (Ushida et al., 2003), and that prostaglandins are partially involved in the gastroprotective actions of $\alpha$-LA (Matsumoto et al., 2001). Given these findings, the stimulation of $\mathrm{PGE}_{2}$ production by $\alpha$-LA in gastric mucus-producing cells might contribute to defense mechanisms of the gastric mucosa, such as blood flow, alkaline secretion, and cell turnover.

Our data from in vitro studies show the possibility that $\alpha$-LA fortifies the mucus gel layer in gastric mucosa in vivo, and we previously observed that $\alpha$-LA increases the mucin content of the mucus gel layer in rat gastric mucosa (Ushida et al., 2003). To obtain sufficient evidence for $\alpha$-LA-mediated enhancement of the mucus barrier, we evaluated the mucus gel layer thickness in rat gastric mucosa using histochemical methods. We also focused on the volume of intramucosal PAS-positive mucus, in addition to gel layer thickness, because a continuous supply of mucus from the intramucosa is important for preservation of the surface gel layer. Orally administered $\alpha$-LA thickened the mucus gel layer in both corpus and antrum mucosa, without reducing intramucosal mucus (Figure $4 \mathrm{~A}$ and $4 \mathrm{~B}$ ). These results demonstrate that activation of mucin secretion and synthesis by $\alpha$-LA leads to increases in the mucus 
gel layer and a stable mucus supply from the intramucosa.

Several biofunctional molecules derived from $\alpha$-LA have recently been reported, including multimeric folding variants to induce apoptosis in tumor cells (Svensson et al., 2000) and polypeptide fragments with bactericidal properties (Pellegrini et al., 1999). To date, however, little information has been obtained regarding active molecules of $\alpha$-LA on mucus metabolism. We reported that the gastric content of orally administered $\alpha$-LA rapidly decreases in rats (Matsumoto et al., 2001), thus suggesting that the intact $\alpha$-LA molecule is not important for expression of gastroprotective activity. In the present study, mucin synthesis and secretion in RGM1 cells did not require the hydrolysis of $\alpha$-LA, indicating that a molecular surface structure of $\alpha$-LA may be important for activating mucus-producing cells. Further study of this possibility is required.

In conclusion, the present findings indicate that $\alpha$ LA stimulates mucin synthesis and secretion in mucusproducing cells, inducing increased thickness of the mucus gel layer in the gastric mucosa. This study strongly suggests that stimulation of mucus metabolism by $\alpha$ LA contributes to its gastroprotective actions.

\section{REFERENCES}

Allen, A., and G. Flemström. 2005. Gastroduodenal mucus bicarbonate barrier: Protection against acid and pepsin. Am. J. Physiol. Cell Physiol. 288:C1-19.

Azuumi, Y., S. Ohara, K. Ishihara, H. Okabe, and K. Hotta. 1980. Correlation of quantitative changes of gastric mucosal glycoproteins with aspirin-induced gastric damage in rats. Gut 21:533536.

Coleman, R. A., S. P. Grix, S. A. Head, J. B. Louttit, A. Mallett, and R. L. Sheldrick. 1994b. A novel inhibitory prostanoid receptor in piglet saphenous vein. Prostaglandins 47:151-168.

Coleman, R. A., W. L. Smith, and S. Narumiya. 1994a. International Union of Pharmacology classification of prostanoid receptors: Properties, distribution, and structure of the receptors and their subtypes. Pharmacol. Rev. 46:205-229.

Daugherty, D. F., M. R. Lucey, and T. Yamada. 1991. Gastric secretion. Pages 233-264 in Textbook of Gastroenterology. Vol. 1. J. B. Lippincott, Philadelphia, PA.

Ding, M., Y. Kinoshita, K. Kishi, H. Nakata, S. Hassan, C. Kawanami, Y. Sugimoto, M. Katsuyama, M. Negishi, S. Narumiya, A. Ichikawa, and T. Chiba. 1997. Distribution of prostaglandin E receptors in the rat gastrointestinal tract. Prostaglandins 53:199-216.

Gill, H. S., and M. L. Cross. 2000. Anticancer properties of bovine milk. Br. J. Nutr. 84:S161-S166.
Håkansson, A., M. Svensson, A. K. Mossberg, H. Sabharwal, S. Linse, I. Lazou, B. Lönnerdal, and C. Svanborg. 2000. A folding variant of $\alpha$-lactalbumin with bactericidal activity against Streptococcus pneumoniae. Mol. Microbiol. 35:589-600.

Håkansson, A., B. Zhivotovsky, S. Orrenius, H. Sabharwal, and C. Svanborg. 1995. Apoptosis induced by a human milk protein. Proc. Natl. Acad. Sci. USA 92:8064-8068.

Hassan, S., Y. Kinoshita, D. Min, H. Nakata, K. Kishi, Y. Matsushima, M. Asahara, H. Y. Wang, A. Okada, T. Maekawa, H. Matsui, and T. Chiba. 1996. Presence of prostaglandin EP4 receptor gene expression in a rat gastric mucosal cell line. Digestion 57:196-200.

Kobayashi, I., S. Kawano, S. Tsuji, H. Matsui, A. Nakama, H. Sawaoka, E. Masuda, Y. Takei, K. Nagano, H. Fusamoto, T. Ohno, H. Fukutomi, and T. Kamada. 1996. RGM1, a cell line derived from normal gastric mucosa of rat. In Vitro Cell. Dev. Biol. Anim. 32:259-261.

Matsumoto, H., Y. Shimokawa, Y. Ushida, T. Toida, and H. Hayasawa. 2001. New biological function of bovine $\alpha$-lactalbumin: Protective effect against ethanol- and stress-induced gastric mucosal injury in rats. Biosci. Biotechnol. Biochem. 65:1104-1111.

Miller, T. A. 1983. Protective effects of prostaglandins against gastric mucosal damage: Current knowledge and proposed mechanisms. Am. J. Physiol. 245:G601-G623.

Mitchell, J. A., P. Akarasereenont, C. Thiemermann, R. J. Flower, and J. R. Vane. 1994. Selectivity of nonsteroidal antiinflammatory drugs as inhibitors of constitutive and inducible cyclooxygenase. Proc. Natl. Acad. Sci. USA 90:11693-11697.

Narumiya, S., Y. Sugimoto, and F. Ushikubi. 1999. Prostanoid receptors: Structures, properties, and functions. Physiol. Rev. 79:1193-1226.

Pellegrini, A., U. Thomas, N. Bramaz, P. Hunziker, and R. von Fellenberg. 1999. Isolation and identification of three bactericidal domains in the bovine $\alpha$-lactalbumin molecule. Biochim. Biophys. Acta 1426:439-448.

Permyakov, E. A., and L. J. Berliner. 2000. $\alpha$-Lactalbumin: Structure and function. FEBS Lett. 473:269-274.

Powell, W. S. 1982. Rapid extraction of arachidonic acid metabolites from biological samples using octadecylsilyl silica. Methods Enzymol. 86:467-477.

Shah, N. P. 2000. Effects of milk-derived bioactives: An overview. Br. J. Nutr. 84:S3-10.

Shimamoto, C., I. Hirata, E. Umegaki, H. Takiuchi, Y. Hiraike, S. Fujiwara, and K. Katsu. 2003. Gastric mucosal cell protection by epidermal growth factor in primary monolayer culture of guinea pig gastric mucous cells. J. Gastroenterol. 38:727-733.

Silen, W. 1987. Gastric mucosal defense and repair. Pages 10551069 in Physiology of the Gastrointestinal Tract. 2nd ed. Raven Press, New York, NY.

Svensson, M., A. Håkansson, A. K. Mossberg, S. Linse, and C. Svanborg. 2000. Conversion of $\alpha$-lactalbumin to a protein inducing apoptosis. Proc. Natl. Acad. Sci. USA 97:4221-4226.

Terano, A., H. Hiraishi, S. Ota, and T. Sugimoto. 1986. Geranylgeranylacetone, a novel anti-ulcer drug, stimulates mucus synthesis and secretion in rat gastric cultured cells. Digestion 33:206-210.

Ushida, Y., Y. Shimokawa, H. Matsumoto, T. Toida, and H. Hayasawa. 2003. Effects of bovine $\alpha$-lactalbumin on gastric defense mechanisms in naive rats. Biosci. Biotechnol. Biochem. 67:577-583.

Wilson, D. E. 1991. Role of prostaglandins in gastroduodenal mucosal protection. J. Clin. Gastroenterol. 13:S65-S71. 